\title{
Object Movement Symmetries in British English Dialects: Experimental evidence for a mixed case/locality approach
}

William Haddican

Queens College-CUNY

bill.haddican@gmail.com

Anders Holmberg

University of Newcastle

anders.holmberg@newcastle.ac.uk

\begin{abstract}
This article reports on a judgment experiment intended to test a prediction of Anagnostopoulou's (2003) seminal proposal concerning locality of A-movement in languages with Theme-Goal orders in active and passive contexts. Results from an experiment with native speakers of UK English show a significant cross-speaker correlation between scores for Theme-Goal orders in active contexts and Theme passives. The results nevertheless indicate a richer inventory of grammars than the two-dialect distribution entailed by a single parametric difference assumed in locality approaches. We propose that these data are best expressed on hybrid Case/locality approach to passive symmetry that models the availability of Theme-Goal orders in both passive and active contexts in terms of the merged position of the probes responsible for agreement on the internal arguments.
\end{abstract}

Keywords: passive, locality, English dialects, applicative, case, A-movement 


\section{Introduction}

Comparative syntactic work on argument structure over of the last two decades has shown that languages with double object constructions (DOCs) pattern in one of two main ways with respect to passive movement. One class of languages, called "asymmetric passive" languages, including Fula, Swahili, Chichewa and Danish, has the property that out of a double object construction, only Goal arguments may passivize (Baker 1988; Bresnan and Moshi 1990; Woolford 1993). We illustrate this pattern with the Danish examples in (1). A second class, traditionally called "symmetric passive" languages, including Norwegian, Swedish, some British English dialects and Kinyarwanda, differs in allowing Goal passivization as well as Theme passivization, as exemplified in the Norwegian sentences in (2) (Baker 1988; McGinnis 1998, 2001; Woolford 1993).
(1) Danish (Holmberg and Platzack 1995)
a. Jens blev givet bogen.
Jens was given book-the
'Jens was given the book.'
b. *Bogen blev givet Jens.

\author{
(2) Norwegian \\ a. Jens ble gitt boken. \\ Jens was given book-the \\ 'Jens was given the book.' \\ b. Boken ble gitt Jens.
}

Generative approaches to this cross-linguistic difference have generally been of two kinds. One approach has explained this contrast in terms of variation in case assignment in passive contexts, typically assuming some process of "case absorption" (Baker 1988; Woolford 1993; Citko 2008). On this approach, derived subjects move to subject position to receive nominative/ergative case, because the object case that would otherwise be assigned to them is absorbed by passive morphology (Baker 1988; Jaeggli 1986; Roberts 1987). Languages and dialects, furthermore, vary in the way case absorption applies in double object constructions: in asymmetric passives only the case otherwise destined for the Goal can be absorbed, with the consequence that only the Goal will passivize in these languages; in symmetric passive languages, on the other hand, passive morphology can absorb case meant for either the Theme or the Goal, with the consequence that either may passivize.

Much recent generative literature has pursued an alternative account in terms of locality. On this approach, Theme passivization in symmetric passive languages is fed by short movement of the Theme to an outer specifier of the Goal, whence it may passivize without hurdling the Goal, as in (3). Where object movement to this escape hatch is unavailable for whatever reason, movement of the Theme to TP is blocked by the intervening Goal (Ura 1996; McGinnis 1998; Bobaljik 2002; Anagnostopoulou 2003; Doggett 2004; Jeong 2007).

\section{(3) The locality approach to Theme passives}

[тр THEME $[\mathrm{T}, \mathrm{T} \ldots[\mathrm{xP}<\mathrm{THEME}>[\mathrm{xp}$ GOAL $[\mathrm{yp}<\mathrm{THEME}>]]]]]$

Crucially at issue for the locality approach is the availability of independent evidence for the short Theme movement shown in (3). In recent literature, two kinds of evidence to this effect have been proposed. First, Anagnostopoulou (2003, cf. Bobalijk 2002) observes that, within Mainland Scandinavian varieties, there is a rough cross-linguistic correlation in the availability of Theme passivization and Theme-Goal orders in object shift (OS): Theme passives and Theme-Goal OS are both available in Swedish and Norwegian, and both 
unavailable in Danish, as illustrated in the Danish and Swedish examples in (4) and (5).

(4) Danish (Anagnostopoulou 2005)

a. Peter viste hende den jo Peter showed her it indeed

'Peter indeed showed it to her.'

b. *Peter viste den hende jo.
(5) Swedish (Anagnostopoulou 2005)

a. Jag gav honom den inte.

I gave him it not

'I didn't give it to him.'

b. Jag gav den honom inte.

Anagnostopoulou $(2003,2005)$ takes the availability of Theme-Goal orders in Swedish/Norwegian OS as evidence that the objects can permute low in the structure as in (3), and that the movement responsible for this order feeds Theme passivization. More recently, Haddican (2010) relates Theme passivization in some British English dialects to Theme-Goal ditransitives in active contexts, as in (6), which are also available in some British English (BrE) dialects. Haddican (2010) develops an analysis of Theme-Goal orders in passive and active contexts, similar in spirit to Anagnostopoulou's proposal for mainland Scandinavian.

(6) She gave it me.

Locality approaches make a strong prediction about cross-speaker variation in languages like Mainland Scandinavian and BrE, namely that acceptability of Theme-Goal orders in active and passive contexts will covary across speakers in these languages. Speakers of these varieties, in other words, should accept Theme passives if and only if they also accept Theme-Goal orders in active contexts. The goal of this paper is to report on a magnitude estimation experiment with native speakers of $\operatorname{BrE}(\mathrm{N}=137)$ designed to test this prediction. The BrE results indicate a significant correlation between Theme-Goal orders in active and passive contexts supporting the locality approach's position that Theme passivization is related to the availability of short Theme movement in these dialects. The data nevertheless indicate a richer inventory of grammars than the two-dialect distribution entailed by a single parametric difference assumed in locality approaches. We propose that the patterns of cross speaker variation observed and restrictions on objects in these constructions are best expressed on a hybrid case/locality approach to passive symmetry, which relates Theme-Goal orders to the merged position of the probes responsible for case on the objects.

Our discussion is organized as follows. Section two of this paper introduces variation in object orders in BrE. Section three reports on an experiment examining cross speaker variation in judgements of Theme passives and Theme-Goal active sentences in BrE dialects. Section four develops an analysis of this variation drawing on locality approaches to object symmetry as well as GB case-based approaches.

\section{Object movement symmetry in British English dialects}

Much of the literature on passive symmetry has discussed the fact that some British English dialects allow for Theme passivization in DOC contexts as illustrated in (7) (Woolford 1993; Anagnostopoulou 2003; Doggett 2004; Citko 2008; Kupula 2011). 
(7) British English dialects ${ }^{1}$
a. \%The ball was given my sister.
(Theme passive)
b. My sister was given the ball.
(Goal passive)

Less widely discussed is the fact that some speakers of dialects in Northwestern and Western England also accept Theme-Goal orders in double object constructions as in (6) (Hughes et al. 2006; Orton et al. 1978). Speakers of these dialects accept these sentences most readily with pronominal objects, although full DP objects are accepted marginally by some speakers as in (8) (Hughes et al. 2006; Hollmann and Siewierska 2007; Myler 2011).

(8) \%She sent the ball my brother.

Before examining the relationship between Theme passivization and Theme-Goal active sentences such as in (6), we first consider the relation of these forms to other ditransitive sentence types in English. In particular, there are at least the following three possible approaches to such sentences. A first possibility is that such sentences are underlyingly DOCs and that some movement operation, perhaps as in (9), is responsible for the inverted order of the arguments.

(9) She gave it $m e<i t>$.

A second possibility is that such sentences are instead prepositional datives with a null or deleted preposition as in (10).

(10) She gave it TO me.

This analysis is lent support by the fact that many speakers of Northwestern and Western dialects also accept sentences with a null allative TO in other contexts such as (11) (Myler 2011, cf. Collins 2007).

(11) I want to go _ Chessington.

Assuming that the to of prepositional dative constructions is the same to under verbs of motion as in (11), then a prepositional dative approach to Theme-Goal ditransitive constructions like (6), suggests a unified approach to these two constructions.

A third possibility is that Theme-Goal orders are neither prepositional datives nor DOCs but rather some third variant. One such alternative is Doggett's (2004:94-96) suggestion that the Theme may be first merged above the Goal, as in (12). (Doggett does not discuss what the first merged position of the Theme is.)

(12) She gave [it [me]].

\footnotetext{
${ }^{1}$ As Larson (1988) and Postal (2004, chapter 4) note, theme passives are also available for some American speakers when the goal is a weak pronoun, as in (i).

(i) The ball was given 'em.

The fact that such sentences are restricted to pronominal goals suggests that this is a partially independent phenomenon, and we set such sentences aside in this discussion.
} 
Haddican (2010) presents evidence suggesting that, for most speakers in these dialect areas, Theme-Goal ditransitives behave like true DOCs and unlike prepositional dative constructions on standard diagnostics. First, for most speakers, Theme-Goal ditransitives behave like DOCs and unlike prepositional datives in that they are poor with latinate verbs (donate, contribute), "manner of communication" verbs (shout, mutter, whisper, scream) and verbs of "continuous imparting of force" (push, haul, lift, pull) as illustrated in (13) (Bresnan and Nikitina 2003; Levin 1993). A few speakers, however, find no difference between (13a) and (13c), suggesting that for these speakers, a representation of Theme-Goal orders as prepositional datives may be available.

(13) a. She $\{$ whispered/donated/hauled $\}$ it to me.

(prepositional dative)

b. She $\left\{{ }^{*}\right.$ whispered $/ *$ donated $/ *$ hauled $\}$ me it.

(DOC)

c. She $\{\%$ whispered $/ \%$ donated $/ \%$ hauled $\}$ it me.

(Theme-Goal ditransitives)

Similarly, for most speakers, Theme-Goal constructions behave like DOCs and unlike prepositional datives in that they are fine with "prevention of possession" verbs (refuse, deny) as in as in (14) (Levin 1993). A smaller set of speakers finds little difference between (14a) and $(14 \mathrm{c})$, again suggesting a representation of these constructions as prepositional datives.
(14) a. * She refused it to me.
b. She refused me it.
c. $\%$ She refused it me.

(prepositional dative)

(DOC)

(Theme-Goal ditransitives)

A third kind of evidence in favor of a DOC analysis of Theme-Goal orders comes from nominalizations. Theme-Goal ditransitives behave like true DOCs, and unlike prepositional datives in being poor in nominalisations (Kayne 1984):

$(15)$ the giving of it to me
$(16) *$ the giving of me it
$(17) *$ the giving of it me

(prepositional dative)

(DOC)

(Theme-Goal ditransitive)

Fourth and finally, for most speakers in the relevant dialect areas, these Theme-Goal constructions behave like true DOCs and unlike prepositional datives in terms of person case constraint (PCC) effects. Across English dialects, DOCs differ from prepositional datives in that, in the former, combinations of two weak object pronouns are degraded if the Theme is first or second person (Anagnostopoulou 2008; Bonet 1991: 185-6; Haspelmath 2004). As Haspelmath (2004), notes, animacy also has an effect: in DOCs, speakers typically prefer inanimate Themes to animate Themes (see also Bresnan and Nikitina 2003). The combined effects of these person and animacy restrictions are illustrated in (18) and (19).

(18)a. Tania showed it to her.

b. Tania showed him to her.

(prepositional dative)

c. Tania showed me to her. (prepositional dative) (prepositional dative)

(19) a. Tania showed her it.

(DOC)

'Tania showed it to her.'

b. ?Tania showed her him.

(DOC)

'Tania showed him to her.'

c. ??/*Tania showed her me.

(DOC) 
'Tania showed me to her.'

Speakers of Northern and Western dialects report similar effects for prepositional dative constructions and DOCs. ${ }^{2}$ These speakers also typically find that Theme-Goal orders are subject to the same person/animacy restrictions as DOCs, as shown in (20).

(20)a. Tania showed it her.

(Theme-Goal ditransitive)

'Tania showed it to her.'

b. ?Tania showed him her.

(Theme-Goal ditransitive)

'Tania showed him to her.'

c.??/*Tania showed me her.

'Tania showed me to her.'

(Theme-Goal ditransitive)

These data therefore show that Theme-Goal ditransitives behave like DOCs and unlike prepositional datives in terms of PCC effects. If PCC effects are a syntactic rather than a morphological phenomenon, then these facts provide further evidence against a prepositional dative approach to Theme-Goal ditransitives (Anagnostopoulou 2003; Rezac 2008). ${ }^{3}$

The following sections describe an experiment intended to test cross-speaker variation in the behavior of Theme-Goal ditransitives in terms of one of these diagnostics - verb class restrictions - as well as the cross-speaker correlation in acceptability of Theme-Goal orders in active and passive contexts. The question therefore is: For the speakers whose Theme-Goal ditransitives are DOCs, is there a correlation between accepting Theme-Goal order and accepting Theme-passives?

\section{A judgment experiment}

\subsection{Method}

Subjects. Participants in the experiment were 137 self-described native speakers of English -90 women and 47 men. Subjects ranged in age from 18 to $63(\mathrm{M}=27.5, \mathrm{SD}=11.6)$. Subjects were recruited online by the researchers in 2010 . We did not require the subjects to be linguistically naïve.

Materials. The experiment consists of two subdesigns. The first subdesign focused on passivization and involved a single factor, derived subject, with two levels-Theme passive and Goal passive. Arguments were all $3^{\text {rd }}$ person pronouns, and verbs were all monosyllabic verbs typically acceptable in both DOCs and prepositional datives. (A list of experimental sentences is provided in the appendix.)

${ }^{2}$ As Haspelmath (2004) notes, some speakers do not find (19c) much degraded. These same speakers however do find (20c) considerably worse. These speakers, then, are reminiscent of Swiss German dialects discussed in Anagnostopoulou (2003, ch. 5) where PCC-effects are sensitive to object order.

${ }^{3}$ The approach to DOCs developed below will nevertheless be inconsistent with Case/Agree approaches to PCC-effects like Anagnostoupoulou (2003) and Rezac (2008), which assume that PCC effects arise because Goal and Theme arguments compete for case from a single phi-probe. In the approach to be developed below, the two internal arguments have separate sources of case. 
The second subdesign focused on object orders in active contexts and crossed two factors: object order, with levels Theme-Goal and Goal-Theme; and verb class, with levels give class (typically acceptable in both DOCs and prepositional datives), and donate class (typically acceptable only with prepositional datives). This second factor was included in order to test for variation across subjects in the behavior of Theme-Goal orders as prepositional datives vs. DOCs. As in the passives subdesign, pronominal arguments were all $3^{\text {rd }}$ person. Goal and Theme interpretations of objects in both subdesigns were biased using animate (for Goals) vs. inanimate (for Themes) pronouns.

Eight lexicalizations were created for each of the two conditions in the passive subdesign and four conditions in the actives subdesign. These were then assigned to one of eight blocks by Latin square, such that each block contained a different lexicalization for each of these six conditions. These blocks were then grouped into eight test sets, with each test set containing 4 blocks; each participant therefore saw each condition four times. The 24 experimental sentences in each test set were pseudorandomized within blocks with 24 filler sentences, half of which are grammatical and half ungrammatical. Subjects were randomly assigned to test sets by the software used.

Procedure. The data were gathered using a magnitude estimation procedure (Stevens 1975; Bard et al. 1996; Sorace and Keller 2005). The modulus sentence is given in (21), which speakers typically find of intermediate acceptability.

(21) ?Who did you see some picture of?

The subjects completed the survey in a self-paced online experiment that took around 10 minutes to complete. Data were gathered using java-based WebExp2.2 software for online experiments (Mayo et al. 2008). The application displayed stimulus sentences oneby-one and did not allow subjects to go back and change or view previous answers. The modulus sentence and the subject's assigned score for the modulus were displayed on each slide along with the stimulus.

The testing session consisted of five parts. The first set of slides elicited background information from the subjects, including sex, hometown and age. The second section was a set of instructions, explaining the magnitude estimation procedure. The third phase was a set of practice slides in which subjects applied the magnitude estimation procedure to line lengths. The fourth section was an additional practice phase in which subjects were introduced to applying this procedure to sentence well-formedness. The final section presented the 30 test sentences.

Following Bard et al.'s (1996) procedure, raw scores were normalized by dividing them by the modulus score. The decadic logarithm of these scores was then taken in order to make data normally distributed and suitable for parametric tests. To correct for possible scale bias in the data, the data were further normalized by converting to z-scores (using means and standard deviations for the 24 filler sentences)(Heycock et al. 2010). This measure indicates the difference in standard deviations of each data point from the speaker's mean filler score.

Results from the second subdesign crossing object order and verb class showed, for most subjects, a pattern of responses consistent with an underlying DOC representation. That is, for most subjects, donate-class verbs are degraded with Theme-Goal orders on a par with DOC orders. A few subjects, however, rated Theme-Goal orders with donate-class verbs on a par with give-class verbs suggesting a representation of these forms as underlying prepositional datives. We removed from the sample 30 subjects for whom the donateclass/give-class difference was not at least as great as the smallest contrast in the sample for 
DOCs. This step served to filter out those subjects for whom Theme-Goal orders behave like covert prepositional datives, whose grammars are irrelevant to our focus.

\subsection{Results}

Figure 1 below shows mean scores and 95\% confidence intervals for the four conditions we are principally concerned with-Theme-Goal and DOC (Goal-Theme) orders (with give-class verbs), and Theme and Goal passives. Zero on the y-axis corresponds to the normalized mean scores taken over the filler sentences (see above). Scores above this line are therefore better than the normalized average filler score and scores below it are worse.

Figure 1: Mean scores and 95\% confidence intervals for four conditions

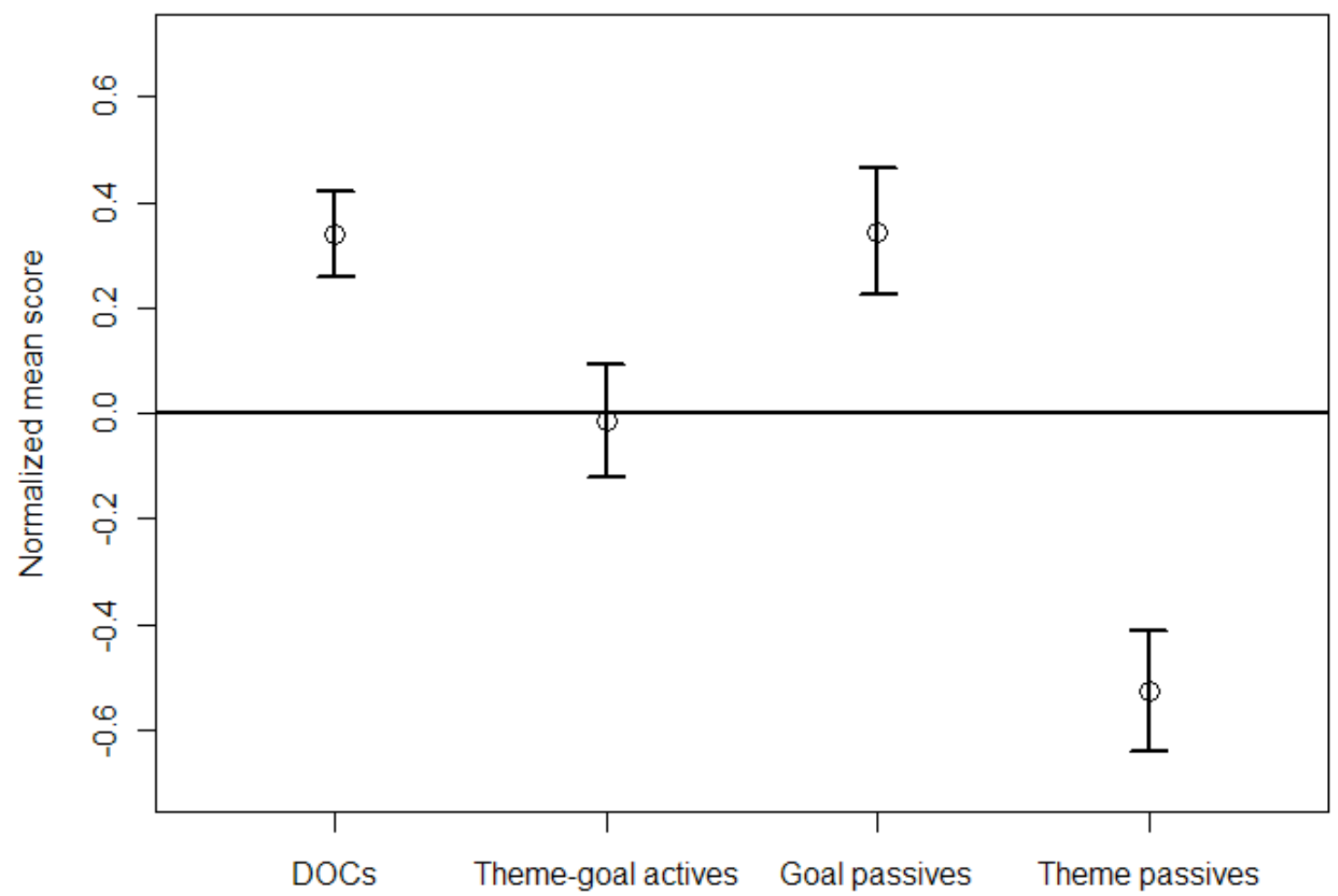

The figure shows that Goal-Theme orders on aggregate are rated better than their Theme-Goal counterparts, an unsurprising result, since presumably all speakers accept GoalTheme orders, but Theme-Goal orders are available in some dialects. Figure 1 also shows that Theme passives are degraded vis-à-vis Theme-Goal orders in active contexts, a crucial fact which we return to shortly.

Now we turn the main question focussed on here, namely the relation between Theme-Goal orders and Theme passives in BrE. We test this by fitting an ordinary least squares regression model with the dependent variable as the contrast between Theme passive scores and Goal passive scores, that is, the average of each speaker's Theme passive scores minus their average for Goal passive scores. We choose this measure as a way of effacing cross-speaker differences in acceptability of passives versus actives, generally. For the same reason, we used the contrast between Theme-Goal and DOC orders in active contexts as a predictor. Other predictors included were subject age, sex and home region. Table 1 
summarizes this model with treatment levels for factors Region (western vs. other) and Sex (men vs. women) in parentheses.

Table 1: Coefficients for a model predicting the contrast between Theme and Goal passivization.

$\begin{array}{lcrcc} & \text { Coefficient } & \text { Std. Error } & \boldsymbol{t} & \operatorname{Pr}(>|\boldsymbol{t}|) \\ \text { Intercept } & -0.832373 & 0.156914 & -5.3047 & <.0001 \\ \text { Actives contrast } & 0.527817 & 0.101915 & 5.1790 & <.0001 \\ \text { Region (West) } & -0.093130 & 0.109918 & -0.8473 & .399 \\ \text { Sex (Men) } & 0.050320 & 0.106010 & 0.4747 & .636 \\ \text { Age } & 0.006828 & 0.004379 & 1.5594 & .122\end{array}$

Residual standard error: 0.5161 on 103 degrees of freedom. Adjusted R-Squared: 0.2262

Table 1 shows a strong positive effect for the actives contrast. That is, how subjects judge Theme-Goal orders in active contexts vis-à-vis DOC orders correlates significantly with their judgements of Theme-passives vis-à-vis Goal passives. None of the betweensubjects variables are significant at $\alpha=.05$.

Figure 2: Mean scores by speaker for Theme-Goal orders in active and passive contexts

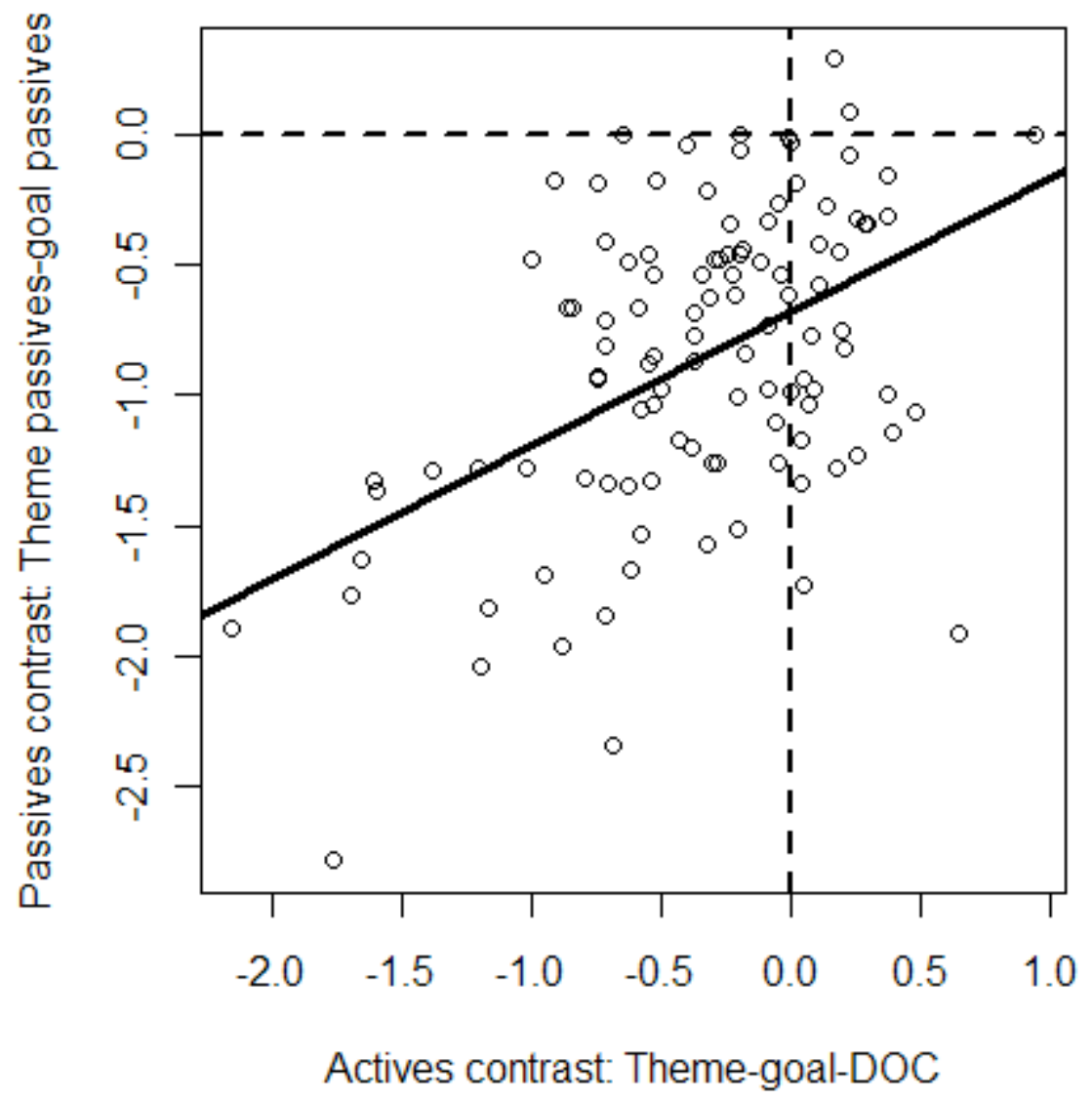

Figure 2 illustrates the correlation between active and passive scores. This figure plots, on the x-axis, the difference between each subject's mean score for Theme-Goal orders and that for Goal-Theme orders in active contexts; the y-axis plots the contrast in individual 
mean scores between Theme passives and Goal passives. Zero on each axis, marked with a broken line, corresponds to identical mean scores for Theme-Goal and Goal-Theme orders on this condition. The solid diagonal line is a regression line, fitted by ordinary least squares regression.

This plot shows that the object order contrast in active contexts correlates with Theme-Goal orders in passive contexts, with quite a bit of residual error. These results, therefore, suggest support for the locality approach in that they show that acceptability of Theme-Goal orders in active contexts helps predict acceptability of Theme passives. Traditional case-based approaches, in contrast, make no such prediction. The distribution in Figure 2, however, suggests a richer inventory of grammars than the two-dialect distribution entailed by a single parametric difference assumed in locality approaches. In particular, locality based approaches to passive symmetry which link Theme passivization to the availability of short Theme movement across the Goal low in the clause, lead us to expect a positive linear relationship between acceptability of Theme-Goal orders in active and passive contexts. Many of the subjects in our sample behave as they should from this perspective, accepting Theme-Goal orders in both contexts, in neither, or somewhere in between for both. However an additional, sizable set of subjects, in the lower right hand corner of Figure 2, accept Theme-Goal orders happily in active contexts but not in passives. This is unexpected from the perspective of a single-parameter approach to object order in these two contexts, and suggests instead that some additional parameter of variation is involved.

Importantly, the logically possible pattern for which evidence is scarcest is one in which Theme-Goal orders in passive contexts is acceptable but not active contexts. The upper left hand corner of Figure 2 is wholly unpopulated, indicating that subjects in our sample accept Theme passives only if they also accept Theme-Goal orders in active contexts to some degree. We treat the possibility of Theme-Goal orders in passive but not active contexts as unattested in the present sample.

The following discussion of English develops an account of these cross-dialectal differences. For convenience, we abstract away from gradience in the availability of each of these patterns, which we take to reflect competition between different grammars following Kroch $(1989,1994)$. We summarize the inventory of grammars to be accounted for in Table 2.

Table 2: Availabilities of Theme-Goal orders in active and passive contexts in BrE dialects

\begin{tabular}{|c|c|c|}
\hline Grammar & $\begin{array}{c}\text { Theme-Goal orders in active } \\
\text { sentences }\end{array}$ & Theme passives \\
\hline 1 & $*$ & $*$ \\
\hline 2 & $\mathrm{Ok}$ & $\mathrm{Ok}$ \\
\hline 3 & $\mathrm{Ok}$ & Ok \\
\hline 4 (unattested) & $*$ & 0 \\
\hline
\end{tabular}

\section{Deriving the inventory of BrE grammars}

\subsection{A mixed case/locality approach}

The experimental results just summarized suggest support for the locality approach in that they seem to provide independent evidence for movement of the Theme to a position above the Goal low in the clause. The data presented in the previous section has shown that 
the availability of Theme-Goal orders in active contexts is crucial to the availability of Theme passives; that is, Theme passivization is only possible if Theme-Goal ditransitives are also available, but not vice-versa. This correlation between Theme-Goal orders in active and passive contexts is unexpected from the perspective of case absorption approaches, which, unlike the locality-based accounts, fail to predict the availability of Theme-Goal orders in active contexts.

The following discussion develops an analysis of Theme-Goal orders in English that follows locality approaches in assuming that passive movement is produced by the same operation responsible for Theme-Goal orders in active contexts (for some speakers). The English dialectal constructions discussed so far, nevertheless, suggest two reasons for skepticism toward pure locality approaches, as in (3), where cross dialectal differences in case/agree operations play no role in accounting for the variation observed. One problem with a pure locality approach is the existence of Grammar 3-that of speakers who accept Theme-Goal orders in active contexts but not passives. On a locality approach, something more is required to explain why objects capable of accessing the escape hatch position cannot raise further to TP.

A second difficulty for a pure locality approach to the English dialect facts discussed here concerns the fact that, for most speakers who accept Theme-Goal ditransitives in active contexts, the Theme must be pronominal; Themes in spec, TP are subject to no such restriction. From the perspective of pure locality based approaches, which explain ThemeGoal orders in terms of movement through an escape hatch, it is difficult to see how to express this pronoun/DP contrast only in active contexts. By contrast, an approach that relates Theme movement in Theme-Goal constructions to nominal licensing, suggests a more familiar understanding of these facts, namely that pronouns require licensing by movement in a way that full DPs do not, akin to e.g. Romance clitic movement.

Haddican (2010), addressing these issues without the benefit of the controlled experimental results presented above, suggests one possible approach to the relationship between Theme-Goal orders in active and passive contexts in the spirit of previous locality approaches. Haddican assumes that the $\phi$-probes responsible for case on both the Theme and Goal in double object constructions are merged on v; the two internal objects are merged in a low applicative (Appl) phrase, the sister of $\mathrm{v}$. The locus of variation between Theme-Goal and Goal-Theme orders is whether the agreement between these probes and their targets trigger movement. In Standard English, these probes trigger no movement, but in Northern and Western English Dialects, the $\phi$-probes will attract the objects to vP. In such dialects, the arguments raise in the order in which they are probed, with the Goal raising first as the closer of the two arguments, and the Theme subsequently to an outer specifier of vP. The inversion of the two arguments therefore comes about as a consequence of the order in which they are probed by $\mathrm{v}$, that is assuming no "tucking in" (Richards 1997). The verb subsequently raises out of vP to a higher head, F, yielding the verb-Theme-Goal word order. This same movement feeds Theme passivisation in passive contexts.

Haddican proposes that the pronominal restriction on Themes in active contexts is a consequence of a dialect-specific, syntax-to-prosody mapping rule that requires FP to spell out as a single prosodic word.

\section{(22) Wrap (FP, Pwd)}

FP can be no bigger than a prosodic word.

Haddican proposes furthermore that phases are phonological units and that material in the complement of $\mathrm{v}$, in the next phase down-complement clauses prepositional 
complements or adjuncts of $\mathrm{V}$, for example - are invisible to (22). This constraint therefore has the consequence of excluding full DP objects in spec, vP, that is, where they appear in the order Theme-Goal, but not when they sit in the complement of $\mathrm{v}$, in the Goal-Theme order; pairs of weak pronouns in spec, vP, which can form a single prosodic word with the verb in F via leaning are also not filtered out. Similarly, assuming chain reduction applies before (22), then full-DP Themes that raise to T via vP will be exempt since the copy of the full DP in spec vP will delete before (22) applies.

Haddican's (2010) approach has two main disadvantages in light of the evidence presented above. First, this approach is ill suited to expressing the Grammar 3 pattern, that of speakers who accept Theme-Goal orders in actives and not passives. Specifically, on this approach, it is difficult to see why movement to TP should be blocked for Themes that have already escaped past the Goal argument to the intermediate position spec, vP. A second disadvantage has to do with the filter in (22) itself, which Haddican (2010) proposes as a dialect-specific property and has no independent motivation. A superior account would express the weak pronoun restriction in Grammars 2 and 3 using independently needed assumptions.

In the remaining discussion we argue that a simpler and empirically more adequate account of the BrE facts is available on an approach that takes the crucial locus of variation between Theme-Goal and Goal-Theme linearizations not to be the availability of escapehatch movement as in (3), but rather the nature of case/agree on the objects in these grammars. In the remaining discussion, we derive the inventory of BrE dialects, considering each of these grammars in turn.

Grammar 1. Following Bruening (2010), we assume that English DOCs have a high applicative structure as shown in (23). The Theme is merged as the complement of the verb and the Goal is introduced as the specifier of a thematic Appl head that takes VP as its sister. The external argument is merged as a specifier of $\mathrm{vP}$. We note that nothing in the analysis to follow crucially depends on the assumption of this structure versus a low applicative approach to English DOCs (Pylkkänen 2002).

\section{(23) Grammar 1: Active contexts}

$$
\text { [vp EA [v' } \mathrm{v}_{[\text {Acc] }}\left[\text { ApplP GOAL [Appl' Appl }{ }_{[\text {Acc] }}[\mathrm{vp} \text { V THEME]]]]] }\right.
$$

We assume that $\mathrm{v}$ and Appl both have uninterpretable person and number features, which give the value Accusative to the case features on the elements with which they agree. In active contexts in this grammar, Appl will therefore agree with the Theme argument, and $\mathrm{v}$ will subsequently probe and agree with the Goal. Little-v has an EPP feature which is satisfied by the external argument. In the absence of any $\mathrm{A}^{\prime}$-movement triggering features, the Goal and the Theme will be spelled out in that order.

In passive contexts, where an external argument is not introduced in Spec,vP, v will be "defective" in that it will lack a person probe required for accusative case on the Goal (Burzio 1986; Chomsky 1995; Legate 2003). Passive v, nevertheless, has an EPP feature in many varieties of English, as shown by constructions (24a,b) (Holmberg 2002): ${ }^{4}$

\footnotetext{
${ }^{4}$ Holmberg (2002) discusses variation among varieties of Mainland Scandinavian which pattern like English in allowing the order EXPL-OBJ-V in passives and those which don't. He argues that passive $v$ retains the properties of a phase head in the former, but not in the latter category. We acknowledge that we have not investigated to what extent the varieties of English discussed in this section accept (24b), or indeed (24a).
} 

a. $\quad$ There were two men arrested last night.
b. There were two men given a prestigious award last night.

We assume that passive $\mathrm{v}$ retains an unvalued number feature probing for a matching valued feature, finding the object of arrest in (24a) and the Goal object in (24b), with the EPP feature attracting it to spec,vP. The number feature by itself, we assume, is not sufficient to value the case of the probed DP, which therefore remains active (in the sense of Chomsky 2000, 2001). (See Taraldsen 1995 and Sigurðsson and Holmberg 2008 on the motivation for split person/number probing. See Anagnostopoulou 2003 and Rezac 2008 for proposals that person and number probing together are required for structural case assignment.) Once in spec, $\mathrm{vP}$, the still active DP is probed and assigned nominative by $\mathrm{T}$. Usually it is attracted by T's EPP feature to spec,TP, although it can remain in spec, $v P$ if the EPP of $\mathrm{T}$ is satisfied by the expletive there, as in $(24 a, b)$.

Thus, in the passive DOC under Grammar 1, the Goal is probed by $\mathrm{v}$ and attracted to spec, $\mathrm{vP}$, where it is probed once more, now by $\mathrm{T}$, assigned Nominative case and (usually) attracted to spec,TP. The Theme will be valued Accusative by Appl in the usual way. We illustrate this proposal in (25), where the probe-goal relations are indicated by lines.

\section{(25) Grammar 1: Passive contexts}

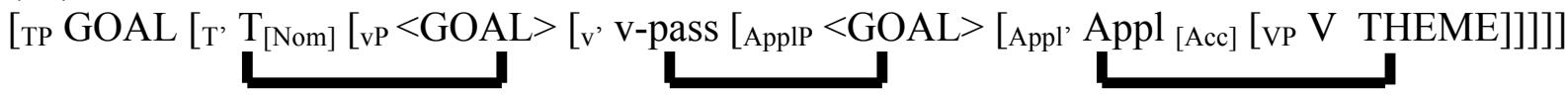

Grammar 2. Grammar 2 differs from Grammar 1 in producing Theme-Goal orders in passive and active contexts. We propose that the crucial locus of variation between ThemeGoal and Goal-Theme orders is whether Appl is merged with an Accusative case-assigning $\phi$ probe, or whether this $\phi$-probe is merged as a higher head, which we take to be a species of "linker" morpheme as in Baker and Collins (2006 cf. Jeong 2007; Johnson 1991). Specifically, Baker and Collins focus on a class of particles in Niger-Congo and Khoisan languages, which obligatorily appear between the internal objects in DOCs. The Kinande example in (26), illustrates such a construction, where the morpheme $y^{\prime}$ appears between the Theme and Goal.

(26) Kinande (Baker and Collins 2006)

Mo-n-a-h-ere omukali $\mathbf{y}^{\prime}$ - eritunda.

Aff-1sS-T-give-Ext woman.1 Lk.l-fruit.5

'I gave a fruit to a woman.'

Baker and Collins argue that the role of such particles is to assign case vP-internally (and sometimes to provide a landing site for movement), but that these morphemes play no role in the thematic interpretation of arguments. We assume, following Baker and Collins, that such morphemes are indeed a category made available by Universal Grammar and are instantiated in some Northern and Western English dialects. Specifically, we propose that these grammars differ minimally in that the person and number probe on Appl in Grammar 1 is merged as a separate linker head, immediately above ApplP in Grammar 2, and assigns Accusative to the Goal from this position. Little-v will also be a probe, and have an [Acc] feature just as in Grammar 1. This structure is illustrated in (27). 
(27) Grammar 2: Active contexts

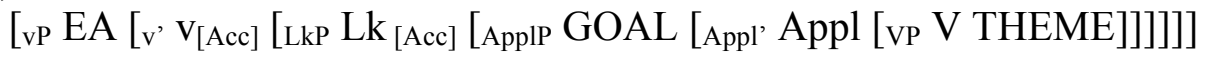

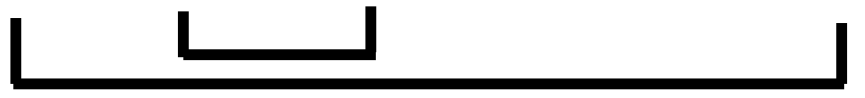

Here, we assume that the higher probe, little-v, can probe the Theme past the Goal because the Goal is assigned case by the closer probe Lk, rendering it inactive, and therefore invisible to the higher probe. We return to this assumption below after discussing the passive in Grammar 2. Lk, we assume, has no EPP feature. Little-v, again, has an EPP feature satisfied by the external argument. We return shortly to the issue of how the Theme-Goal word order is derived from this structure.

As in Grammar 1, passive little-v in Grammar 2 will be deficient, being merged without an unvalued person feature, yet retaining an unvalued number feature which will probe for a matching valued feature, and retaining the EPP-feature. Lk retains its casevaluing capacity in the passive, assigning accusative case to the Goal. This renders the Goal inactive, and thereby transparent to probing/agreement. The effect is that the Theme is probed by little-v, and attracted to spec, vP, but not assigned case. Once in spec,vP it can be probed by $\mathrm{T}$, assigned Nominative case, and attracted to spec, TP by the EPP-feature on $\mathrm{T}$. We illustrate this in (28), again indicating the probe-goal relations.

(28) Grammar2: Passive contexts

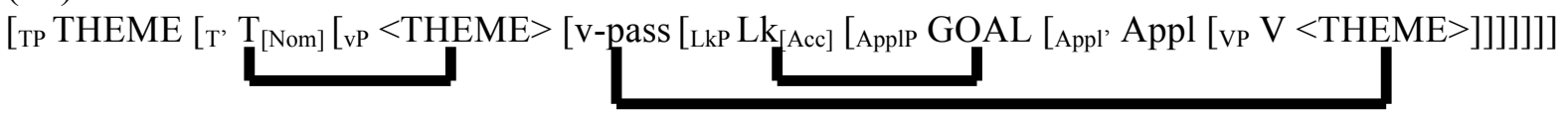

(27) and (28) both appear to represent "defective intervention" configurations (Chomsky 2000, 2001, 2005) as the higher probe, little-v, probes past a matching goal, the Goal argument. From the perspective of our proposal, Grammar 2 sentences are reminiscent of other well-known cases where $\mathrm{T}$ probes past an intervening experiencer, namely raising sentences of the kind in (29) (McGinnis 1998; Collins 2005; Hartman 2012).

(29) John seems to Mary to be nice.

(Collins 2005)

Nevertheless, as Hartman (2012) notes, other contexts including tough-movement constructions and passive movement out of ECM complements appear to show intervention effects, as illustrated in (30) and (31)

(30) John was said (*to me) to be guilty.

(Hartman 2012)

(31) John is annoying (*to those boys) to talk to.

(Hartman 2012)

A complete model of (non)-intervention effects in A-movement is beyond the scope of this paper. What (29) shows, however, is that English does allow for some contexts where T can probe (and attract) an argument across an intervening experiencer/goal argument.

The defective intervention effect that Chomsky (2000, 2001, 2005) discusses is primarily based on Icelandic constructions where a dative argument (DAT) intervening between $\mathrm{T}$ and a nominative argument (NOM) prevents agreement between $\mathrm{T}$ and NOM, blocking A-movement of NOM across DAT. Holmberg and Hróarsdóttir (2004) discuss 
constructions such as (32), where the dative argument blocks agreement between matrix $\mathrm{T}$, hosting the raising verb, and the embedded nominative argument (see also Sigurðsson and Holmberg 2008).

$$
\begin{aligned}
& \text { Pað virðist/*virðast einhverjum manni [hestarnir vera seinir]. } \\
& \text { it seems/seem some man.DAT the.horses.NOM be slow } \\
& \text { 'It seems to some man that the horse are slow.' }
\end{aligned}
$$

Broekhuis (2007) compares these structures with their counterparts in Dutch, where agreement between T and NOM is possible across DAT. He argues that the difference is that DAT is a "quirky subject" in Icelandic but not in Dutch. Being quirky means that DAT is necessarily probed by $\mathrm{T}$, like a subject. This means that it must be active at the point when $\mathrm{T}$ is merged and probes for a valuator, and therefore it will block Agree between $\mathrm{T}$ and a lower argument. In Dutch, on the other hand, DAT is not quirky, but has its Case feature assigned independently of T; see Broekhuis (2007). As such it does not prevent agreement between T and a lower NOM. This is what we claim is the situation in (27) and (28): the Goal argument is probed and assigned its Case by Lk, and therefore does not affect the relation between little-v and the Theme in (27) and (28).

A further set of assumptions is required to express the fact that Theme-Goal orders in active contexts are restricted to weak pronominal Themes. Note, in particular, that Themes cannot be stressed in Theme-Goal constructions (33).

(33) * She gave IT/THEM me.

We adopt Roberts' (2010a) theory of clitic-incorporation by agreement (see also Roberts 2010b; Holmberg 2010). This is based on the (uncontroversial) assumption that pronominal clitics/weak pronouns are $\phi$ Ps, consisting, as they do, of $\phi$-features exclusively. When probed by a head with matching but unvalued $\phi$-features, $\phi$ Ps end up as copies of the probe in that all their feature values will also be represented in the probe, as a result of the valuation. Roberts (2010a) refers to this as incorporation of the pronoun in the head containing the probe. The result is formally a two-member argument chain. As such, it will undergo "chain reduction" at spell-out, where typically only the highest copy of a chain is spelled-out (Nunes 2004). Hence the features of the pronominal argument are spelled out at the position of the probing head; the pronoun is, in this sense, incorporated in the probing head. ${ }^{5}$ Agree between a probe and a lexical DP will not result in a chain, as the lexical DP will always have some features which are not represented at the probe, in particular its lexical root, and therefore the DP will never be a copy of the probing head. Likewise, Agree between a probe and a focused pronoun will not result in a chain, since the focus feature will not be represented in the probe, and thus the pronominal goal will have to be spelled out. A lexical DP or focused pronoun may move to the vicinity of the probing head but only if the probe has an EPP-feature.

In Grammar 2, just as in Grammar 1, little-v's EPP feature in the active DOC is satisfied by the external argument. Lk, we assume, has no EPP-feature. This accounts for the fact that the Theme-Goal order in the active DOC is possible only with weak pronominal

\footnotetext{
${ }^{5}$ Roberts (2010a) applies this theory to object clitics in Romance, in particular. Roberts (2010b) and Holmberg (2010) employ it to account for subject pro-drop in languages with rich agreement.
} 
arguments. Following Roberts' (2010a) theory of pronoun incorporation, we submit that the inverted order of Theme and Goal derived in Grammar 2 is not derived by movement, but by incorporation. The probes $\mathrm{v}$ and $\mathrm{Lk}$, are made up of a set of unvalued $\phi$-features, plus, at least in the case of $\mathrm{v}$, some additional features including a verbal categorial feature and a feature assigning a theta-role to the external argument. As shown above in (27), the unvalued $\phi$ features of the probe, $\mathrm{Lk}$, are valued by the interpretable $\phi$-features of the closest matching goal, that is the Goal argument, which is assigned Accusative Case in return. This allows v to probe past the now inactive Goal argument, and have its $\phi$-features valued by the Theme. As a result of the feature valuation, the Goal is now a copy of Lk, while the Theme is a copy of $\mathrm{v}$, in that all the features of the Goal and the Theme are represented, with identical values, in Lk and $\mathrm{v}$, respectively. The probing heads and their goals make up argument chains derived by Agree alone, without movement. At spell-out, the lower copies are deleted. This is shown in (34).

\section{(34) Grammar 2: weak pronoun incorporation (active contexts)}

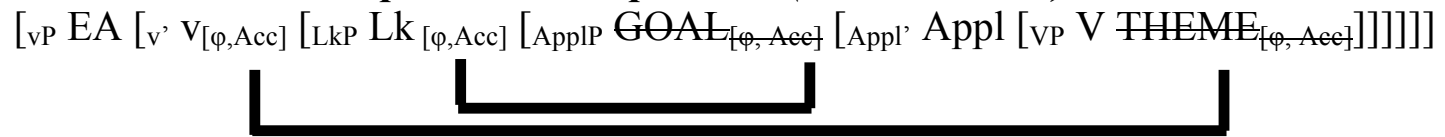

In the passive, incorporation of the Theme in $\mathrm{v}$ is not possible since passive $\mathrm{v}$, by hypothesis, lacks a person feature. The Theme can, however, be attracted by v's EPP feature, making it accessible to probing by $\mathrm{T}$ and movement to spec,TP.

Our test sentences for inversion in active contexts only considered inversion of two weak pronominal objects. However, for many speakers of BrE who accept inversion in active contexts, the crucial condition appears to be that the Theme should be a weak pronoun. For these speakers there is a sharp division between (35) and (36).

(35) a. She gave it me.

b. She gave it ME.

c. $\%$ She gave it her brother. ${ }^{6}$

(36) a. * She gave the ball me.

b. $\quad *$ She gave the ball ME.

c. * *She gave IT me.

d. *She gave the ball her brother. ${ }^{7}$

\footnotetext{
${ }^{6}$ Some speakers that accept theme goal orders with a weak pronominal theme, also require or prefer a weak pronominal goal, while other speakers accept sentences like (35c) fully (Hughes et al. 2006). We do not have any controlled data on this variation, but note that, from the perspective of our proposal, those speakers who accept Theme-Goal orders with pronominal but not full-DP themes show a restriction much like that discussed in detail by Anagnostopoulou (2003) for several languages, where cliticization obviates locality in Amovement. See also Larson (1988). We do not attempt to account for these facts here.

${ }^{7}$ We noted in section 2 that sentences like (36d) are acceptable for some speakers in some northern and western dialects (Myler 2011). It remains to be investigated whether, for such speakers, these sentences are derived from an applicative/DOC structure or are prepositional datives.
} 
Consider first the case of (35a) in terms of Roberts' (2010a) theory. V-to-v movement and additional operations at the TP and CP level derive a sentence such as (35a). In the case of $(35 b, c)$ the Theme is incorporated in $v$, as in (35a), but the Goal is not, as it has a focus feature in (35b) and a lexical root in (35c). In all three cases, the inverted order is derived without any movement. Since v's EPP-feature is satisfied by the external argument, the Theme object cannot move past the Goal, so the ungrammatical (36 a,b,c,d) will not be derived.

An important fact about the cross-speaker variation described above about which our analysis will have nothing to say is that, while only some UK speakers allow for Theme-Goal orders in passive and active contexts (Grammar 2), presumably all native speakers allow for Goal-Theme orders (Grammar 1). We see no motivation for viewing this as a formal problem, but rather take it to be a sociolinguistic fact. The formal diachronic syntax work of Kroch and colleagues of the last 20 years has shown that semantically equivalent syntactic representations, "Grammars", vary across speakers and speaker-internally much like other kinds of dialectal variants, as in the variation between walking and walkin' for example (Fruehwald et al. 2009; Kroch 1989, 1994, 2001; Pintzuk 1991; Santorini 1992). From this perspective, the nature of the cross-speaker lexical (featural) variation responsible for the contrasts between for Grammar 1 and Grammar 2 is a sociolinguistic problem, and not one that we should expect a theory of syntax to answer. We therefore take it as a dialectological fact that all speakers have the standard Grammar 1 pattern where an Accusative-assigning $\phi$ probe is merged on Appl, while only a subset of these also allow for the dialectal Grammar 2 pattern by which this probe can be merged as a separate Linker head.

Grammar 3. Grammar 3 is that of speakers who accept Theme-Goal orders in active contexts but not passives. We propose that this grammar differs minimally from Grammar 2 in that Lk does not assign Accusative case in the passive. Active contexts in Grammar 3 will be exactly as described for Grammar 2, allowing Theme-Goal order, but only as a result of incorporation, so we omit discussion of such sentences here. The effect of Lk failing to assign Accusative in the passive DOC is that the Goal object is not rendered inactive, and therefore will be probed by v's number feature, and attracted by v's EPP feature. This, in turn, means that the Theme will not be assigned case at all, which is to say that Grammar 3 does not have a passive DOC. This is represented in (37). Assuming that Lk and $\mathrm{v}$ both have a number feature but no Accusative-assigning person-feature, the Goal will be probed by $\mathrm{V}$ and $\mathrm{Lk}$, and subsequently, by virtue of movement to spec, $\mathrm{PP}$, by $\mathrm{T}$, assigning it Nominative case. This is of no consequence, though, since the Theme will not be assigned any case, and the derivation will crash.

\section{(37) Grammar 3: Passive contexts}

$\left[\mathrm{TP}\left[\mathrm{T}, \mathrm{T}_{[\mathrm{Nom}]}[\mathrm{vp}\right.\right.$ V-pass [LkP Lk [ApplP GOAL[Appl' Appl [vP V THEME]]]]]]]

A way to see the difference between Grammars 2 and 3 is that Lk retains the thematic caseassigning capacity of Appl in Grammar 2, making it insensitive to the active/passive distinction, while Lk is a structural case-assigner in Grammar 3. This makes no difference in the active construction, but does in the passive construction.

Again, the apparent fact that all speakers of UK English accept Goal-Theme orders in both active and passive contexts indicates that speakers with the Grammar 3 pattern just described will be bi-dialectal in Grammar 1. That is, Grammar 3 speakers will also allow for DOC structures with the Acc-assigning probe on Appl, rather than on a Linker head outside ApplP, and thereby derivation of Goal-Theme passives. As discussed above, we see no 
reason to expect the distribution of these Grammars across speakers to follow from a theory of argument structure, but rather take it to be a sociolinguistic fact about UK dialects.

*Grammar 4. Finally, *Grammar 4 is the unattested pattern in our sample, whereby Theme passivization is available but not Theme-Goal orders in active contexts. This pattern is correctly excluded under the assumptions introduced, since Theme passivization is crucially dependent on the same vP-internal structure responsible for Theme-Goal orders in active contexts - namely an Accusative assigning linker head above Appl. We note that, in principle, there could be additional parameters of variation that would make possible the * Grammar 4 pattern. This would be the outcome of a grammar which has a linker head assign case to the Goal in the passive, thereby making it possible for $\mathrm{v}$ to probe the Theme, attracting it to spec, $\mathrm{vP}$, but would not have incorporation of pronominal objects as an option in the active DOC. This could be the case in a language or dialect which does not have pronouns of the weak or clitic variety consisting of nothing but a set of $\phi$-features, but otherwise has its parameters set as in Grammar 2. No such variety of English is in evidence in the data set reported on here.

The assumptions introduced above therefore correctly express all and only the attested grammars in our results.

\subsection{Theme-goal linearization variation elsewhere in Germanic varieties}

An issue raised by the preceding discussion is the extent to which the analysis should extend to cross-speaker variation in object linearizations in Swedish and Norwegian dialects. Theme-Goal order is at least marginally acceptable with weak pronouns in connection with object shift for some Swedish and Norwegian speakers, as in (38) (Holmberg 1986: 207; Hellan and Platzack 1999; Anagnostopoulou 2003; but see Josefsson 2003):

$$
\begin{aligned}
& \text { Swedish } \\
& \text { \%Hon gav den mej inte. } \\
& \text { she gave it me not } \\
& \text { 'She didn't give me it.' }
\end{aligned}
$$

Theme-Goal order in passives is also found in Norwegian and (though more marginally) in Swedish (Holmberg and Platzack 1995: 215-221). To date, no controlled experimental work has focused on cross-speaker variation in object orders in object shift and passive contexts in Swedish/Norwegian, akin to that presented here for BrE. Future work might usefully address this possibility. There are reasons, however, to suspect that the Scandinavian pattern may be partially distinct from the BrE facts discussed above. In Scandinavian, the inversion seems to be dependent on object shift, an operation that moves weak pronominal objects out of vP, across the negation and sentence adverbs, on the condition that the main verb moves as well (Holmberg's generalization; Holmberg 1986, 1999). ${ }^{8}$ Inversion is therefore not found in contexts such as $(39 a, b)$ in any varieties of Scandinavian, as far as we are aware (although we acknowledge that this remains to be properly investigated). In (39a,b), the main verb, and consequently the objects, remain within vP (Holmberg and Platzack 1995; Vikner 1995).

\footnotetext{
${ }^{8}$ This is one popular understanding of this phenomenon, which will do for the purposes of the present discussion. See Holmberg $(1986,1999)$ for arguments that the proper characterization of HG is not in terms of verb movement but is rather phonological in nature: object shift may not apply across phonologically visible elements. The restriction to shifting only weak pronouns does not apply in Icelandic, and, in fact, not uniformly across all Mainland Scandinavian dialects either; see Bentzen et al. (2007).
} 
Swedish

a. $\quad$ Hon borde inte ha gett den mej.

she should not have given it me

Intended: 'She should not have given it to me.'

b. *Det är bäst att inte ge den mej.

it is best to not give it me

Intended: 'It is best not to give it to me.'

In the relevant dialects of English, the corresponding constructions are well formed.

(40) a. She shouldn't have given it me.

b. I need you to give it me.

The landing site (or incorporation site, if we are right) of the inverted Theme in English is within vP, as indicated in the previous section, but outside vP in Scandinavian. ${ }^{9}$

We may speculate that this is related to a categorial distinction between the inverting pronouns in English and Scandinavian. If our analysis of the active Theme-Goal construction in $\mathrm{BrE}$ dialects is right, the inverting pronouns are clitics, incorporated in the probing heads, little- $\mathrm{V}$ and Lk, respectively. The pronouns undergoing object shift in Scandinavian, according to Holmberg (1986, 1999), Holmberg and Platzack (1995) and Vikner (1995), are weak pronouns undergoing phrasal movement, not clitics undergoing head movement (or incorporation). If the inversion in (38) is indeed the result of object shift, then the similarities between inversion in English and Scandinavian may be more apparent than real. It is not impossible, for example, that some variety of Scandinavian instantiates Grammar 4, as discussed above in section 4.1 .

\section{Conclusion}

This article reports on a judgment experiment testing cross-speaker correlations in acceptability of object orders in active (DOC) and passive contexts in British English. The results show a positive correlation in scores, as predicted by locality/escape-hatch approaches to passive symmetry. The data nevertheless show a richer inventory of grammars than the two-dialect pattern predicted by locality approaches. We argue that this fact, together with pronoun restrictions on objects in active contexts is better expressed on a hybrid Case/locality approach to passive symmetry, rather than a pure locality account as proposed in previous minimalist work (Ura 1996; McGinnis 1998; Bobaljik 2002; Anagnostopoulou 2003; Doggett 2004). We have identified three different grammars of British English, distinguished by two linked parameters: whether Accusative case can be assigned to the Goal object in the DOC by a linker head, and if so, whether the linker head assigns thematic or structural case.

\footnotetext{
${ }^{9}$ Anagnostopoulou (2003) proposes that the movement responsible for the inversion of the theme and goal in Norwegian/Swedish is prior to OS. To account for the unavailability of sentences like (39a,b), Anagnostopoulou (2003:158) proposes that this movement is licit only in contexts where it feeds a further movement step, namely OS or passive movement. See Richards (1997: 127-162) for a discussion of other cases of movement, which may be constrained in this way.
} 


\section{Acknowledgements:}

We thank first and foremost the participants in our experiment and three very insightful JCGL reviewers, and the JCGL editor Susi Wurmbrand, whose comments helped to improve the paper considerably. Thanks also to David Adger, Dora Alexopoulou, Mark Baltin, Diane Blakemore, Elisabet Engdahl, Paul Foulkes, Sam Hellmuth, Caroline Heycock, Richard Kayne, Frank Keller, Tony Kroch, Erez Levon, Neil Mayo, Alec Marantz, Neil Myler, Diane Nelson, Bernadette Plunkett, Leendert Plug, Milan Rezac, Devyani Sharma, George Tsoulas, Kevin Watson, Melinda Whong and audiences at U. of Leeds, Colóquio de Gramática Generativa XX, CGSW 25, NYU and Stony Brook University. We also thank Frank Keller for randomization and blocking scripts. Work on this paper was supported by ESRC grant number 061-25-0033 and by a grant from the Spanish Ministerio de Economía y Competividad (FF2011-26906). All errors are our own.

\section{References:}

Anagnostopoulou, Elena. 2003. The Syntax of Ditransitives. Berlin: Mouton de Gruyter. Anagnostopoulou, Elena. 2005. Holmberg's Generalization and Cyclic Linearization: Remarks on Fox and Pesetsky. Theoretical Lingusitics 31:95-110.

Anagnostopoulou, Elena. 2008. Notes on the Person Case Constraint in Germanic (with special reference to German). In Agreement Restrictions, eds. Roberta D'Alessandro, Susann Fischer, Gunnar Hrafn Hrafnbjargarson, 15-48. Berlin: Mouton de Gruyter..

Baker, Mark. 1988. Incorporation. Chicago: University of Chicago Press.

Baker, Mark and Chris Collins. 2006. Linkers and the internal structure of vP. Natural Language and Linguistic Theory 24:307-354.

Bard, Ellen G., Dan Robertson, and Antonella Sorace. 1996. Magnitude estimation of linguistic acceptability. Language 72:32-68.

Bentzen, Kristine, Anna-Lena Wiklund, Gunnar Hrafn Hrafnbjargarson, and Porbjörg Hróarsdóttir. 2007. Rethinking Scandinavian verb movement. Journal of Comparative Germanic Linguistics 10:203-233.

Bobaljik, Jonathan. 2002. A-chains at the PF-interface: Copies and 'Covert ' Movement. Natural Language and Linguistic Theory 20:197-267.

Bonet, Eulalia, 1991. Morphology after syntax: Pronominal clitics in Romance. $\mathrm{PhD}$ thesis, MIT.

Bresnan, Joan, and Lioba Moshi. 1990. Object asymmetries in comparative Bantu syntax. Linguistic Inquiry 21:147-145.

Bresnan, Joan, and Tatiana Nikitina. 2003. On the Gradience of the Dative Alternation. Ms. Stanford University.

Broekhuis, Hans. 2007. Does Defective Intervention Exist? In Linguistics in the Netherlands 2007, eds. Bettelou Los and Marjo van Koppen, 49-61. Amsterdam: John Benjamins.

Bruening, Benjamin. 2010. Ditransitive Asymmetries and a Theory of Idiom Formation. Linguistic Inquiry 41: 519-562.

Burzio, Luigi. 1986. Italian syntax. Dordrecht: D. Reidel, Chomsky, Noam. 1995. The Minimalist Program. Cambridge, MA: MIT Press.

Chomsky, Noam. 2000. Minimalist Inquiries: The Framework. In Step by Step: Essays on Minimalist Syntax in honor of Howard Lasnik, eds. Roger Martin, David Michaels and Juan Uriagereka, 89-155. Cambridge, MA: MIT Press.

Chomsky, Noam. 2001. Derivation by Phase. Ken Hale: A Life in Language, ed. Michael Kenstowicz, 1-52. Cambridge, MA: MIT Press.

Chomsky, Noam. 2005. Three factors in language design. Linguistic Inquiry 36: 1-22.

Citko, Barbara. 2008. A (New) Look at Symmetric and Asymmetric Passives, NELS 
Handout.

Collins, Chris. 2005. A smuggling approach to raising in English. Linguistic Inquiry 36: 289-298.

Collins, Chris. 2007. Home sweet home. In NYU Working Papers in Linguistics, vol 1, eds. Lisa Levinson and Oana Savescu.

Doggett, Teal Bissell. 2004. All things being unequal: Locality in Movement. $\mathrm{PhD}$ thesis, MIT.

Fruehwald, Josef., Jonathan Gress-Wright and Joel Wallenberg, 2009. Phonological Rule Change:The Constant Rate Effect, Proceedings of NELS 40. Amherst: GLSA.

Haspelmath, Martin, 2004. Explaining the Ditransitive Person-Role Constraint: A usagebased Approach. Constructions 2: 1-71.

Haddican, William. 2010. Theme-goal ditransitives and Theme passives in British English dialects. Lingua 120: 2424-2443.

Hartman, Jeremy. 2012. (Non-) intervention in A-movement: Some cross-constructional and cross-linguistic considerations. Linguistic Variation 11:121-148.

Hellan, Lars, and Christer. Platzack. 1999. Pronouns in Scandinavian languages: An overview. In Clitics in the Languages of Europe, ed. Henk van Riemsdijk, 123-142.

Berlin: De Gruyter.

Heycock, Caroline, Antonella Sorace, and Zakaris Svabo Hansen. 2010. V-to-I and V2 in subordinate clauses: an investigation of Faroese in relation to Icelandic and Danish. Journal of Comparative Germanic Linguistics 13:61-97.

Hollmann, Willem and Anna Siewierska. 2006. Ditransitive clauses in English with special reference to Lancashire dialect. Ms. University of Lancashire.

Holmberg, Anders. 1986. Word order and syntactic features in the Scandinavian languages and English. Ph.D. Thesis. University of Stockholm.

Holmberg, Anders. 1999. Remarks on Holmberg's Generalization. Studia Linguistica 53: 139.

Holmberg, Anders. 2002. Expletives and Agreement in Scandinavian Passives. Journal of Comparative Germanic Linguistics 4: 85-128.

Holmberg, Anders and Thorbjörg Hróarsdóttir. 2004. Agreement in dative constructions in Icelandic. Lingua 113: 997-1019.

Holmberg, Anders. 2010. Null Subject Parameters. In Parametric Variation: Null Subjects in Minimalist Theory, ed. Teresa. Biberauer, Anders Holmberg, Ian Roberts, and Michelle Sheehan, 88-124. Cambridge/New York: Cambridge University Press.

Holmberg, Anders and Christer Platzack. 1995. The Role of Inflection in Scandinavian Syntax. Oxford/New York: Oxford University Press.

Hughes, Arthur, Peter Trudgill and Dominic Watt. 2006. English Accents and Dialects. London: Hodder Arnold.

Jaeggli, Osvaldo. 1986. Passive. Linguistic Inquiry 17:593-599.

Jeong, Youngmi. 2007. Applicatives: Structure and interpretation from a minimalist perspective. Amserdam/Philadelphia: Benjamins.

Johnson, Kyle. 1991. Object Positions. Natural Language and Linguistic Theory 9: 577636.

Josefsson, Gunlög. 2003. Four myths about Object Shift in Swedish - and the Truth.... In Grammar in Focus: Festschrift for Christer Platzack 18 November 2003 Volume 1, eds. Lars-Olof Delsing, Cecilia Falk, Gunlög Josefsson, and Halldór Á. Sigurðsson, 199-207. Department of Scandinavian Languages, Lund University.

Kayne, Richard S. 1984. Unambiguous paths. In: Connectedness and binary branching. 129164. Dordrecht: Foris. 
Kroch, Anthony. 1989. Reflexes of grammar in patterns of language change. Language Variation and Change 1:199-244.

Kroch, Anthony. 1994. Morphosyntactic variation. In Proceedings of the 30th Annual Meeting of the Chicago Linguistics Society, ed. Katharine Beals, 180-201. Chicago: Chicago Linguistic Society.

Kroch, Anthony. 2001. Syntactic change. In The Handbook of Contemporary Syntactic Theory, eds. Mark Baltin and Chris Collins, 699-730. Oxford: Blackwell.

Kupula, Mikko. 2011. A phase extension approach to double object constructions Evidence from Modern Greek. Studia linguistica 65: 147-169.

Larson, Richard. 1988. On the double object construction. Linguistic Inquiry 19:335-391.

Legate, Julie Anne. 2003. Some interface properties of the phase. Linguistic Inquiry 34: 506516.

Levin, Beth. 1993. English Verb Classes and Alternations. A Preliminary Investigation. Cambridge, MA: MIT Press.

Mayo, Neil, Martin, Corley and Frank Keller. 2008. WebExp2, www.webexp.info/.

McGinnis, Martha. 1998. Locality in A-Movement. PhD Thesis MIT.

McGinnis, Martha. 2001. Phases and the syntax of applicatives. In Proceedings of NELS 31, eds. Min-Joo Kim and Uri Strauss, 333-349. Amherst:GLSA.

Myler, Neil. 2011. Come the pub with me: Silent TO in a Dialect of British English. In NYU Working Papers in Linguistics, vol. 3, eds. Jim Wood and Neil Myler.

Nunes, Jairo. 2004. Linearization of Chains and sideward movement. Cambridge, MA:MIT Press.

Pintzuk, Susan. 1991. Phrase structures in competition: variation and change in Old English word order, PhD thesis, University of Pennsylvania.

Postal, Paul. 2004. Skeptical Linguistic Essays. Oxford: Oxford University Press.

Pylkkänen, Liina. 2002. Introducing Arguments. Cambridge, MA: MIT dissertation.

Rezac, Milan. 2008. The syntax of eccentric agreement: the Person Case Constraint and absolutive displacement in Basque. Natural Language and Linguistic Theory 26:61106.

Richards, Norvin. 1997. What moves where when in which language? PhD Thesis, MIT.

Roberts, Ian. 1987. The Representation of Implicit and Dethematized Subjects. Dordrecht: Foris.

Roberts, Ian. 2010a. Agreement and Head Movement: Clitics, Incorporation and Defective Goals. Cambridge, MA:MIT Press.

Roberts, Ian. 2010b. A deletion analysis of null subjects. In Parametric variation: Null subjects in minimalist theory, eds. Teresa Biberauer, Anders Holmberg, Ian Roberts, and Michelle Sheehan, 58-87. Cambridge/New York: Cambridge University Press.

Santorini, Beatrice 1992. Variation and change in Yiddish subordinate clause word order. Natural Language and Linguistic Theory 10:595-640.

Sigurðsson, Halldór Ármann and Anders Holmberg. 2008. Icelandic dative intervention:

person and number are separate probes. In Agreement restrictions, eds. Roberta D'Alessandro, Susann Fischer, Gunnar Hrafn Hrafnbjargarson, 251-80. Berlin: Mouton de Gruyter.

Sorace, Antonella and Frank Keller. 2005. Gradience in linguistic data. Lingua 115:14971524.

Stevens, Stanley S. 1957. On the psychophysical law. Psychological Review 64:153-181.

Taraldsen, Knut. T. 1996. Reflexives, pronouns, and subject/V agreement in Icelandic and Faroese. In Microparametric syntax and dialect variation, eds. James Black and Virginia Motapanyane, 189-212. Amsterdam: John Benjamins. 
Ura, Hiroyuki. 1996. Multiple Feature-Checking: A Theory of Grammatical Function Splitting. PhD thesis, MIT.

Vikner, Sten. 1995. Verb movement and expletive subjects in the Germanic languages. Oxford: Oxford University Press.

Woolford, Ellen. 1993. Symmetric and asymmetric passives. Natural Language and Linguistic Theory 11:679-728. 
Appendix I: Experimental sentences

1. Passives subdesign

Lexicalization 1

Condition

Theme pass.

Goal pass.

Lexicalization 2

Condition

Theme pass.

Goal pass.

Lexicalization 3

Condition

Theme pass.

Goal pass.

\section{Lexicalization 4}

Condition

Theme pass.

Goal pass.

Lexicalization 5

Condition

Theme pass.

Goal pass.

Lexicalization 6

Condition

Theme pass.

Goal pass.

Lexicalization 7

Condition

Theme pass.

Goal pass.

Lexicalization 8

Condition

Theme pass.

Goal pass.

\section{Actives subdesign}

\section{Lexicalization 1}

\section{Condition}

Theme-Goal, give class

Theme-Goal, donate class

DOC, give class

DOC, donate class

Lexicalization 2

\section{Condition}

Theme-Goal, give class

Theme-Goal, donate class

DOC, give class

DOC, donate class

\section{Sentence}

It was given him.

He was given it.

\section{Sentence}

They were shown her.

She was shown them.

\section{Sentence}

It was sent them.

They were sent it.

\section{Sentence}

It was sold him.

He was sold it.

\section{Sentence}

It was posted him.

He was posted it.

\section{Sentence}

They were lent her.

She was lent them.

\section{Sentence}

It was brought them.

They were brought it.

\section{Sentence}

It was handed him.

He was handed it.

\section{Sentence}

Tim lent it her.

Tim lifted it her.

Tim lent her it.

Tim lifted her it.

\section{Sentence}

John showed it him.

John lowered it him.

John showed him it.

John lowered him it. 


\section{Lexicalization 3}

\section{Condition}

Theme-Goal, give class

Theme-Goal, donate class

DOC, give class

DOC, donate class

Lexicalization 4

\section{Condition}

Theme-Goal, give class

Theme-Goal, donate class

DOC, give class

DOC, donate class

\section{Lexicalization 5}

\section{Condition}

Theme-Goal, give class

Theme-Goal, donate class

DOC, give class

DOC, donate class

Lexicalization 6

\section{Condition}

Theme-Goal, give class

Theme-Goal, donate class

DOC, give class

DOC, donate class

Lexicalization 7

\section{Condition}

Theme-Goal, give class

Theme-Goal, donate class

DOC, give class

DOC, donate class

\section{Lexicalization 8}

\section{Condition}

Theme-Goal, give class

Theme-Goal, donate class

DOC, give class

DOC, donate class

\section{Sentence}

Mike sold it her.

Mike whispered it her

Mike sold her it.

Mike whispered her it.

\section{Sentence}

Sam pass it them.

Sam pulled it them.

Sam passed them it.

Sam pulled them it.

\section{Sentence}

Paul handed it him.

Paul screamed it him.

Paul handed him it.

Paul screamed him it.

\section{Sentence}

Ann sent it him.

Ann repeated it him.

Ann sent him it.

Ann repeated him it.

\section{Sentence}

Susan gave it them.

Susan donated it them.

Susan gave them it.

Susan donated them it.

\section{Sentence}

Charlotte brought it him.

Charlotte dragged it him.

Charlotte brought him it.

Charlotte dragged him it. 